\title{
"Eram de Terra Seus Corpos... de Água Seus Sonhos": Incidências de um processo criativo com as(os) Mbya-Guarani na formação de professoras(es) de dança
}

\author{
Crystian Danny da Silva Castro \\ Universidade Federal de Santa Maria - UFSM, Santa Maria/RS, Brasil \\ E-mail: crystiandcastro@gmail.com \\ Mônica Corrêa de Borba Barboza \\ Universidade Federal de Santa Maria - UFSM, Santa Maria/RS, Brasil \\ E-mail: monica.cborba@gmail.com \\ Odailso Berté \\ Universidade Federal de Santa Maria - UFSM, Santa Maria/RS, Brasil \\ E-mail: odailso.berte@ufsm.br
}

\section{Resumo}

Este trabalho apresenta reflexões acerca das possibilidades artístico-pedagógicas no campo das artes da cena, em específico a dança, voltadas para a formação de professoras(es). Tais discussões emergem do Projeto de Extensão "De terra seus corpos", iniciado no ano de 2018 e vinculado ao Curso de Dança - Licenciatura da UFSM. Por meio de diferentes processos criativos, deu-se a remontagem do espetáculo Som e Luz em Corpos, que consiste na coreografia/encenação do tradicional espetáculo de Som e Luz, do Sítio Histórico de São Miguel Arcanjo. Essa obra tem sido apresentada por um elenco composto de estudantes indígenas da Aldeia Guarani Tekoá Koenjú e acadêmicas(os) Universidade Federal de Santa Maria. À luz das compreensões da Ecologia de Saberes (SANTOS, 2010), Epistemologias do Sul (SANTOS, 2019) e Pedagogia da Autonomia (FREIRE, 2015), buscou-se articular um fazer-pensar dança que promova diálogos horizontais entre as epistemologias que operam dentro das universidades e os diversos saberes que são produzidos pelos Mbya-Guarani. Com esse trabalho, percebe-se um enriquecimento na formação das(os) licenciandas(os), sobretudo no que tange à docência em Arte e a elaboração de práticas artístico-pedagógicas contemporâneas, alicerçadas em uma perspectiva de valorização da diversidade e reconhecimento da cultura Guarani na sua história e potencial criativo.

\section{Palavras-chave}

Processos Artístico-Pedagógicos em Dança. Comunidade Tekoá Koenjú. Ecologia de Saberes. Epistemologias do Sul. Pedagogia da Autonomia.
This work presents reflections on the artisticpedagogical possibilities in the field of performing arts, specifically Dance, aimed at the formation of teachers. Such possibilities emerge from the "Of earth their bodies" Extension Project, started in 2018 and linked to the Dance Course of (name of the institution). Through different creative processes, the show "Sound and Light in Bodies" was reassembled, which consists of the choreography/staging of the traditional show of Sound and Light, from the Sítio Histórico de São Miguel Arcanjo. This work has been presented by a cast composed of indigenous students from Aldeia Guarani Tekoá Koenjú and academics from (name of the institution). In the light of understandings of Ecology of Knowledge (SANTOS, 2010), Epistemologies of the South (SANTOS, 2019) and Pedagogy of Autonomy (FREIRE, 2015), we sought to articulate a dance-making that promotes horizontal dialogues between the epistemologies that operate within universities and the diverse knowledge acquired by Mbya-Guarani. With this work, there is an enrichment in the training of undergraduate students, especially with regard to teaching in Art and the development of contemporary artistic-pedagogical practices, based on a perspective of valuing diversity and recognition of culture Guarani in its history and creative potential.

Keywords

Artistic-Pedagogical Processes. Tekoá Koenjú Community. Knowledge Ecology. Epistemologies of the South. Pedagogy of Autonomy. 
"De terra seus corpos": um projeto que estende os saberes em dança

O fazer-pensar que move os processos artístico-pedagógicos na formação de professoras e professores de dança torna-se o eixo basilar deste estudo. Na busca por compreender que abordagem pedagógica é esta que perpassa a produção do conhecimento no campo das artes da cena - em especial a dança - articulamos diferentes reflexões advindas da experiência artística, isto é, do processo criativo, a fim de encontrar possibilidades críticas, autônomas e emancipatórias para atuar na formação destas(es) licenciandas(os).

No ano de 2018, no Laboratório Investigativo de Criações Contemporâneas em Dança (LICCDA) ${ }^{1}$, criamos o Projeto de Extensão intitulado "De terra seus corpos", implementando um convênio entre a Universidade Federal de Santa Maria (UFSM), a Prefeitura Municipal de São Miguel das Missões/RS e a Fundação de Apoio à Tecnologia e Ciência (FATEC). Nos processos de estudo e criação do LICCDA, buscamos desenvolver processos artístico-pedagógicos alicerçados nos saberes e fazeres de cada indivíduo, coletivizando-os, pois compreendemos que no conhecimento docente em dança não há como separar o saber artístico do saber pedagógico, considerando que ambos se hibridizam em um fazer no qual o ensino deve ser por meio da Arte (BARBOZA, 2019).

Refletindo sobre a prática docente das(os) licenciadas e licenciados em dança, para que esta seja efetivamente de arte e não "sobre arte" (ICLE, 2012), é necessário que este futuro professor/professora seja também artista. Isso implica em propor-

1 O Laboratório Investigativo de Criações Contemporâneas em Dança (LICCDA) é um grupo de pesquisa, um coletivo de artistas - discentes, docentes e pesquisadores de pós-graduação dos cursos de Dança da Universidade Federal de Santa Maria - engajado com a pesquisa artística no campo da dança. O grupo, criado em 2014 pelo Prof. Dr. Odailso Berté, tem criado e apresentado obras de dança contemporânea em espaços como escolas públicas de educação básica, teatros, feiras e demais eventos, contribuindo para a ampliação e democratização do acesso a bens culturais de dança desenvolvidos dentro da Universidade pública. cionar a esta(e) aluna(o) a experiência do fazer em dança, do processo de criação, das práticas artísticas que envolvem os conhecimentos teóricos, das questões didáticas, da vivência cênica, da possibilidade de (re)invenção de si e da sua prática docente desde o cerne artístico que lhe constitui. O conhecimento pedagógico aliado à experiência em dança contribui para uma formação à docência que pode ser investigada durante e após a graduação.

Esses pressupostos nos levam às seguintes questões: como percebemos o fazer em dança no ambiente acadêmico? Que danças poderão/deverão atravessar a formação das(os) futuras(os) professoras e professores na área? Que danças criaremos na escola com nossas alunas e alunos? Como pensar pedagogicamente esse fazer em dança a partir da ótica da formação desses profissionais? Interessa-nos, portanto, propor diferentes estratégias e instâncias formativas para o campo da docência em dança, permeando os diálogos entre a dança que se produz dentro e fora da universidade. O Projeto "De terra seus corpos" nasce do desejo de encontrar, construir uma Ecologia de Saberes e uma Epistemologia do Sul (SANTOS, 2019) em dança, junto a corpos diferentes na cultura e nos modos de se mover.

Entre os objetivos do referido projeto de extensão estava o de "desenvolver um conjunto de ações extensionistas de pesquisa, ensino e criação artística envolvendo acadêmicos e professores da UFSM e a comunidade local e regional de São Miguel das Missões" (UFSM, 2018). Na primeira fase do projeto, 2018, as ações desenvolvidas aconteceram na UFSM junto às(os) treze acadêmicas(os)-bailarinas(os) do LICCDA, com o processo de criação para remontagem do espetáculo Som e Luz em Corpos²,

2 O espetáculo Som e Luz em Corpos foi originalmente criado no ano de 2005 pelo artista Odailso Berté, junto à extinta Cia Sarx de Teatro-dança, de Santo Ângelo - RS, em parceria com a Secretaria Municipal de Turismo de São Miguel das Missões - RS. Esta consiste na coreografia e encenação do tradicional espetáculo de Som e Luz do Sítio Histórico de São Miguel Arcanjo, e é realizada como uma grande intervenção a céu aberto junto às ruínas desse local. 
tendo por base o texto e a música do espetáculo de Som e $L u z^{3}$ apresentado no Sítio Histórico de São Miguel Arcanjo, em São Miguel das Missões, RS. O Som e Luz em Corpos é um espetáculo de dança contemporânea que consiste na coreografia e encenação do referido espetáculo de Som e Luz.

$\mathrm{Na}$ segunda fase do projeto, no ano de 2019, ampliamos o raio de ação com jovens estudantes residentes da cidade de São Miguel das Missões e da Aldeia Guarani Tekoá Koenjú, através de oficinas de dança que objetivaram a inclusão desses no elenco do espetáculo Som e Luz em Corpos. $\mathrm{Na}$ continuidade deste escrito, buscamos refletir sobre as etapas desse processo artístico-pedagógico, enfocando os aspectos formativos das(os) licenciandas(os) em dança por meio da experiência artística realizada e compartilhada com as e os estudantes e professoras(es) Mbya-Guarani.

Para subsidiar este estudo, sobretudo no que se refere às reflexões sobre o desenvolvimento do projeto e seu efeito na formação das(os) acadêmicas(os) de Dança - Licenciatura da UFSM, recorremos às nossas observações e anotações, enquanto professores e coordenadores, elaborados ao longo do processo - registros durante e após o processo criativo, sobre as apresentações e oficinas de dança realizadas, bem como outros materiais como artigos, cartilha e programa do espetáculo já publicados. Nesse sentido, compartilhamos a seguir alguns dos pressupostos teóricos que norteiam nosso trabalho, para então destacar as perspectivas mais relevantes sobre cada uma das fases do trabalho, discutindo o impacto na formação das(os) futuras(os) professoras(es) de dança e para nós enquanto seus formadores(as), vislumbrando assim possibilidades pedagógicas para o campo das artes da cena.

3 O espetáculo de Som e Luz foi criado em 1978, pelo Governo do Estado do Rio Grande Sul e repassado ao Município de São Miguel das Missões. O texto desta obra é de autoria de Henrique Grazziotin Gazzana, a música de Jorge Preiss e a programação de luzes de Gerry Marques.

\section{"De ar a formosura de suas vestes":}

as "Epistemologias do Sul" e a docência em dança

Quando o estudioso português Boaventura Sousa Santos (2019) conceitua o termo "Epistemologias do Sul", nos provoca a pensar (e nos impele a agir com este propósito) em um possível enfretamento à hegemonia historicamente fundamentada nos modos colonialistas de pesquisar, ensinar e aprender, cristalizados e amplamente difundidos pelos preceitos da ciência moderna. Esta proposição de Santos (2019) acerca das "Epistemologias do Sul", tem sido imprescindível em nossos processos artístico-pedagógicos, uma constante inspiração/suporte teórico para pensarmos criticamente acerca da nossa prática como professores(as) formadores(as) atuantes na Licenciatura em Dança.

Para Santos, o movimento de refletir sobre nossas práticas desde o "Sul" trata "de identificar e valorizar aquilo que muitas vezes nem se quer figura como conhecimento à luz das epistemologias dominantes", destacando a "dimensão cognitiva das lutas de resistência contra a opressão e o conhecimento que legitima esta mesma opressão" (SANTOS, 2019, p. 18). Os pressupostos epistemológicos colonialistas, fortemente sedimentados e ainda vigentes em diversas práticas formativas e de produção de conhecimento, estão diretamente ligados a um projeto maior, de sociedade, que exclui, menospreza, invisibiliza e deslegitima os saberes/fazeres dos grupos sociais oprimidos em virtude de um longo processo colonizador da nossa história. Sendo assim, lutar contra o patriarcado, o colonialismo, o capitalismo e seus efeitos, torna-se tarefa de todo educador e educadora progressista que compreende, portanto, a urgência e a potência de constituir novas epistemologias.

Os processos históricos de colonização analisados por Santos (2019) como sendo as "Epistemologias do Norte", conquistaram corpos, territórios e, ainda hoje, em nossa sociedade, tomam espaços com base em um pensamento eurocêntrico e conservador que se alastra nas mais diversas práticas sociais, entre elas, os processos educacionais e for- 
mativos nas universidades, escolas, igrejas, associações e outros espaços. Se consideramos a formação de professoras(es) isso se torna crucial, pois na grande maioria das práticas realizadas nesse campo, incluindo os currículos em suas estruturas, percebemos o impacto e a dimensão dessas epistemologias e, também, que sempre houve formas de resistência - movimentos de luta social - a essas imposições.

No que tange a dança, tais epistemologias eurocêntricas ainda predominam nas concepções que consideram as formas de produção artísticas advindas dos costumes e gostos das cortes e elites europeias, sendo o balé clássico um exemplo característico. Essa forma de dança é ainda exaltada em detrimento, por exemplo, das danças populares, das danças autóctones dos povos originários, dos guetos e vilas por todo o mundo. Considerando esse contexto histórico, ainda fortemente arraigado na contemporaneidade, vemos a importância de analisar e contextualizar essas danças hegemônicas de forma crítica, articulando modos (processos e procedimentos) para (re)encontrar, (re)conhecer, valorizar e visibilizar as danças de diferentes povos, sujeitos e grupos culturais. Acessar as danças, ou os modos de se mover dos corpos e povos originários, e evidenciá-los em suas mais diversas potencialidades, é um modo de articular a "Ecologia de Saberes" (SANTOS, 2010). Isso nos leva a, por exemplo, no contato com os Mbya-Guarani, conhecer e gerar formas mais horizontais (ou ainda, transversais) e plurais para entender a dança como área de conhecimento, como arte e como prática cultural, com diferentes funções e significações que vão muito além da dança cênica.

Santos considera que a ciência moderna acabou por realizar um verdadeiro "epistemicídio", constituindo-se uma "vibrante e inesgotável fonte de progresso tecnológico e desenvolvimento capitalista" que "arrasou, marginalizou ou descredibilizou todos os conhecimentos não científicos que lhe eram alternativos" (SANTOS, 2010, p. 155). Olhando para nossas vivências como professoras(es) e artistas, tomadas(os) por essa reflexão e pela metáfora de uma constelação de conhecimentos (SANTOS, 2010), per- cebemos que a dança, como saber feito pelo/no/com o corpo, pode provocar o questionamento, formas de luta e resistência frente a esses modos tradicionais de compreender o que é conhecimento legítimo, gerando formas outras de acessar, reconhecer e construir saberes, a partir da basilar relação corpo - mundo.

Os pressupostos de Santos $(2010 ; 2019)$ têm nos ajudado a, na formação de professores no campo da dança, não recorrer à práticas e formas de movimento que padronizam os corpos e as danças, mas sim, à modos de pensar-fazer dança afeitos às experiências que constituem os corpos em suas subjetividades e particularidades, articulando assim novas práticas epistemológicas. Na formação em dança, "o modo como exercemos a docência, em cada movimento, é conteúdo que ensina sobre ser professor(a), queiramos ou não" (BARBOZA, 2019, p. 69). Tanto quanto fomentar as Epistemologias do Sul e questionar as Epistemologias do Norte, importa construir caminhos metodológicos que materializam estes pressupostos, engajar nossos esforços para que tais princípios aconteçam também nos percursos formativos dos discentes com os quais trabalhamos, e isso requer um exercício contínuo de crítica e reflexão sobre nossas ações docentes.

Reschke destaca que, enquanto formadoras(es), nossa docência "é a didática em ação e deve ser explorada tanto nos saberes práticos como nos seus pressupostos teóricos" (RESCHKE, 2014, p. 108). A articulação teoria-prática, prática-teoria, na dança, consiste em uma retroalimentação constante, entendendo que a professora ou o professor formador "ensina pelo exemplo, pelo que faz junto com as suas alunas e os seus alunos, pelas metodologias que utiliza, pelas estratégias de relação que põe em prática e pelos modelos de avaliação que instaura" (Idem, 2014 p. 108). Há que se enfrentar as dicotomias herdadas da ciência moderna que não só separam como sobrepõe a teoria sobre a prática, infiltrando-se fortemente nos processos de ensino e aprendizagem.

No campo da dança, Marques destaca que a ou o artista-docente é aquela(e) que, "não abandonando suas possibilidades de criar, interpretar, 
dirigir", tem "como função explícita a educação em seu sentido mais amplo" (MARQUES, 2008, p. 112). Sendo antes de tudo artista, isso não basta para que seja uma professora ou professor na área da dança. Há que se formar, conhecer e compreender os saberes artístico-pedagógicos, exatamente para que seja possível perceber e problematizar, no sentido de desestabilizar os padrões modernistas e as epistemologias hegemônicas incrustados nos modos de ensinar e aprender dança.

O projeto "De terra seus corpos" tem nos ajudado a refletir sobre essas questões e apontar caminhos para a construção de Epistemologias do Sul partindo da revisão de nossas práticas artístico-pedagógicas e ampliando isso para o contexto artístico e educacional mais amplo. Propor uma pedagogia para as artes da cena está intimamente conectado com o que juntos, alunas(os) e professoras(es), experienciamos no fazer artístico. Acreditamos que uma prática artístico-pedagógica que não possibilita o pensamento sensível, crítico e performativo ofusca a potência de transformação que a arte possui. Por isso, dançamos e criamos junto às nossas alunas(os), aprendendo com o movimento constante de reflexão que move nossa prática.

A seguir, descreveremos e comentaremos aspectos do processo criativo das duas fases do Projeto "De terra seus corpos", refletindo acerca de como os pressupostos tratados até aqui entremearam-se em nossas ações e, assim, contribuíram na formação dos sujeitos envolvidos.

\section{"Como fogo sua vontade de viver": Metodologias "do Sul" em práticas artístico-pedagógicas}

A primeira fase do projeto "De terra seus corpos" deu-se entre as(os) estudantes integrantes do Laboratório Investigativo de Criações Contemporâneas em Dança, na UFSM, consistindo no processo criativo para a remontagem do espetáculo Som e Luz em Corpos (BERTÉ; BORBA; CASTRO, 2019). A criação se deu de modo coletivo e compartilhado, em relação com os pressupostos artístico-pedagógicos que nos mobilizam como formadores(as), e inspirada nos processos criativos da coreógrafa alemã Pina Bausch (1940-2009), especialmente em como esta propunha perguntas às(aos) bailarinas(os) para que, com base em suas vivências, as respondessem em forma de movimento. Duas ações criativas foram propostas às(aos) estudantes integrantes do LICCDA para impelir sua criação de movimentos a partir de suas singularidades e perspectivas como artistas e professoras(es) em formação, instigando-as(os) a imbricar seus saberes e fazeres, de forma crítica, autônoma e emancipatória nesse processo artístico.

Tendo como referência a proposta de Berté (2015), da dança contempop - que consiste em um processo criativo de dança contemporânea baseado na relação corpo e imagem -, a primeira ação criativa ocorreu a partir do uso de imagens. Em uma visita ao Museu das Missões, localizado no Sítio Histórico de São Miguel Arcanjo, onde está abrigada e exposta a coleção de esculturas em madeira feitas pelos Guarani sob orientação dos Jesuítas na época dos Sete Povos das Missões (1682-1750), no Sul do Brasil, as(os) estudantes escolheram três esculturas/imagens nas quais se inspiraram para criar movimentos. Posteriormente, esses movimentos foram trabalhados para compor diferentes momentos da coreografia no espetáculo, como, por exemplo, na coreografia Flor Incomum (Fig. 1).

Figura 1 - Espetáculo Som e Luz em Corpos. Sítio Histórico de São Miguel Arcanjo. Dezembro/2018.

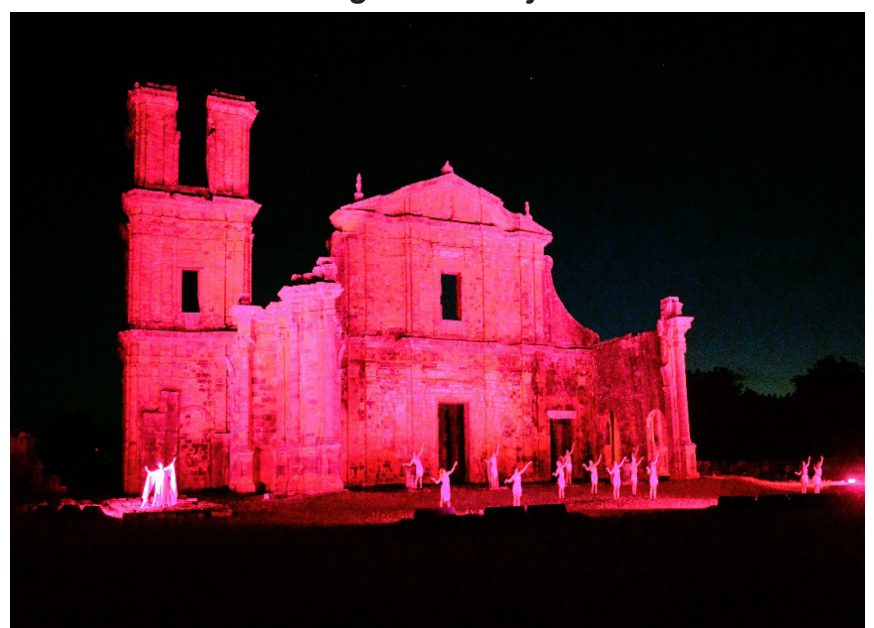

Fonte: Foto de Marconi Flach. Arquivo dos autores. 
No texto do espetáculo, quando a personagem Ruínas fala: "Nós, Ruínas, e vós, Terra, vimos brotar uma flor incomum e solitária na primavera humana. Parimos e acalentamos a nação dos Guarani" (GAZZANA, 1978, p. 13), as(os) estudantes bailarinas(os), aludindo às(aos) Guarani, aparecem pela primeira vez em cena, em frente da antiga catedral, e executam a coreografia Flor Incomum. Nesta, aparecem movimentos que foram deliberadamente inspirados no gestual de esculturas como: a santa de mãos postas e com o tronco inclinado para frente; Santo Isidro com o braço erguido; e o Anjo com os braços levemente abertos e pousados no ar. Pensar o movimento de dança a partir do gestual e do movimento próprios da imagem/escultura, instiga a(o) intérprete-criador(a) a conhecer essa obra de arte em sua história e transcender essa referência, dando-Ihe outra forma de existência, qual seja, a de dança. E assim procedemos nas criações de muitas outras cenas do espetáculo Som e Luz em Corpos.

Já na segunda ação criativa, da primeira fase do projeto, fizemos um cuidadoso estudo do texto e roteiro do espetáculo de Som e $L u z$, escrito por Henrique Gazzana Grazziotin em 1978. Nosso intuito era, a partir das palavras e situações narradas, dar movimento às imagens suscitadas pelo texto, construindo a dramaturgia corporal de cada personagem em relação à sonoridade vocal das suas vozes (que são gravadas em áudio desde 1978), à música e aos espaços do sítio onde acontecem as cenas, conforme a demarcação da programação de luzes e a disposição dos refletores e dos remanescentes arqueológicos. A partir desse estudo, compartilhado com as(os) estudantes intérpretes-criadoras(es), nasceram as movimentações de diferentes personagens do espetáculo, como Sepé Tiarajú, Terra, Ruínas, Padre Antônio Sepp, entre outros, instaurando um modo singular de dança-teatro.

Os diferentes procedimentos criativos desenvolvidos para esta remontagem do espetáculo atenuaram afetos e reflexões das(os) estudantes, e nossas, enquanto formadores(as), acerca do contexto cultural, sociopolítico e artístico presen- tes no Sítio Histórico de São Miguel, deflagrando potencialidades para fazer-pensar práticas artístico-pedagógicas desde a experiência in loco.

Foi um processo de muitas descobertas. Sempre morei na região das missões, mas a história havia sido me contada de outra forma, por uma outra visão, então, visitar o museu, apreciar as esculturas, ter contato com o povo indígena, conhecer a aldeia, e conviver com a comunidade de São Miguel, foram essenciais para que eu entendesse toda a essência e importância desse projeto. E com essas sensações, memórias e obras, pensar e elaborar as criações, essas que vinham a partir das imagens, e também de lugares muitos profundos, entre sentimentos, pensamentos, e até mesmo confronto de ideias que tive... [...] dançar lá foi uma oportunidade de rever meus objetivos com a Dança, e como artista-docente, um imenso e potente projeto como esse, traz novos olhares e visões sobre meu papel como professora, em saber ouvir mais, incluir mais e respeitar mais, dar mais voz e vez aqueles muitas vezes esquecidos, e oportunizar experiências enriquecedoras e transformadoras como esta que dizem muito sobre nossa história. (informação verbal) ${ }^{4}$.

O relato da acadêmica-bailarina supracitado demonstra a relevância das ações do projeto em sua formação docente e na construção de suas abordagens de criação em dança. Percebe-se, portanto, que este caminho artístico-pedagógico tem sido importante para refletirmos acerca da potência do processo criativo/artístico, desenvolvido de maneira compartilhada, e o que pode proporcionar na formação das(os) licenciandas(os) em dança. Isso nos remete à Pedagogia da Autonomia proposta por Paulo Freire (2015). Com seu teor crítico, afetivo e revolucionário, este pensador e educador brasileiro apostou em um fazer pedagógico que valoriza a experiência dos sujeitos (educandos e educadores) como caminho para formas de construção dialógicas e horizontais do conhecimento.

4 Entrevista com Samara Weber Schmidt, acadêmica do oitavo semestre do curso de Dança - Licenciatura da UFSM e integrante do LICCDA, realizada em 02 de setembro de 2020. Arquivo dos autores. 
A Pedagogia da Autonomia faz-se um pressuposto basilar no campo artístico e, especialmente, no ensino de arte, perpassando e reverberando nos processos-produtos gerados em nossos fazeres. Nessas "práticas, tempos e espaços de aprender" que permitem "expandir, exercer e valorizar a autonomia tanto do educando como do educador" (CASTRO; BERTÉ, 2017, p. 386), acreditamos estar construindo, junto com as(os) licenciandas(os) em dança, metodologias do "Sul", saberes e práticas artístico-pedagógicos que repercutirão em suas ações como futuras(os) professoras(es).

\section{"Como fogo os seus amores":} dançar com as(os) Mbya-Guarani

Com o decorrer das apresentações do espetáculo Som e Luz em Corpos, para além da boa recepção dos turistas e visitantes do sítio, a comunidade local de São Miguel das Missões passou a assistir esta obra com mais frequência, justamente por ela conter os corpos, os 'personagens encarnados', ao vivo, diferente do que estavam habituados (vozes e luzes). Perante a motivação da comunidade, para a segunda fase do projeto "De terra seus corpos", propusemos um trabalho formativo objetivando compartilhar as práticas artístico-pedagógicas experimentadas pelas(os) estudantes da UFSM na primeira fase do projeto e compor um elenco local para o espetáculo.

Criamos um programa de oficinas quinzenais de dança, desenvolvido no período de abril a julho de 2019 , em quatro modalidades para alunas(os) e professoras(es) da rede pública e pessoas da comunidade: Oficinas preparatórias (para crianças); Oficinas Juvenis (destinadas ao ensino médio); Oficinas pedagógicas (às professoras(es) de Arte e Educação Física); e Oficinas para a Comunidade. As oficinas foram realizadas com o apoio das Secretarias de Educação e de Turismo do município e, devido às particularidades do espetáculo em ser uma intervenção artística a céu aberto no sítio histórico e com apresentações noturnas, a composição do elenco aconteceu com os participantes das Oficinas Juvenis e da Comunidade.

Desde a primeira fase do projeto, tínhamos a intenção de, ao remontar esse espetáculo criado e exibido entre os anos de 2005 e 2009, não mais "falar sobre" as e os Guarani (executando uma obra que trata da sua história), mas desenvolver algo junto delas(es), que sempre nos olhavam curiosas(os) durante os ensaios e apresentações no sítio, enquanto vendiam seu artesanato. No entanto, não tínhamos claro como nos aproximar e o que propor. Mas logo no início da divulgação das oficinas, um fato curioso aconteceu. Ao saberem das oficinas de dança, as e os estudantes da Escola Estadual Indígena de Ensino Fundamental Igineo Romeu Koenjú, solicitaram, junto à Secretaria de Educação, que uma oficina de dança fosse ofertada a elas(es) e realizada na Aldeia Guarani Tekoá Koenjú (situada a $40 \mathrm{Km}$ da cidade de São Miguel das Missões). Desafiadas(os) por esse genuíno e audaz pedido, sem pestanejar, porém com muitas interrogações acerca de como proceder, aceitamos seu pedido, e é sobre essa experiência e seu impacto na formação das(os) licenciandas(os) em dança que refletiremos na continuidade do presente escrito.

Ao programar esta oficina com as(os) doze estudantes Mbya-Guarani, na faixa etária entre 10 a 16 anos, muitas questões atravessaram nosso planejamento: como realizar um trabalho artístico-pedagógico sem cair no erro de nos tornarmos colonizadores desses corpos por meio da dança? Como desenvolver um novo encontro de culturas em que a dança pudesse ser uma criação compartilhada? A dança poderia acontecer como uma celebração desse encontro de culturas? Entre essas e outras questões, iniciamos esse processo que tanto tem nos questionado, modificado, emocionado... 
Figura 2 - Oficina de dança na Escola Estadual Indígena de Ensino Fundamental Igineo Romeu Koenjú. Aldeia Tekoá Koenjú. Abril/maio de 2019.

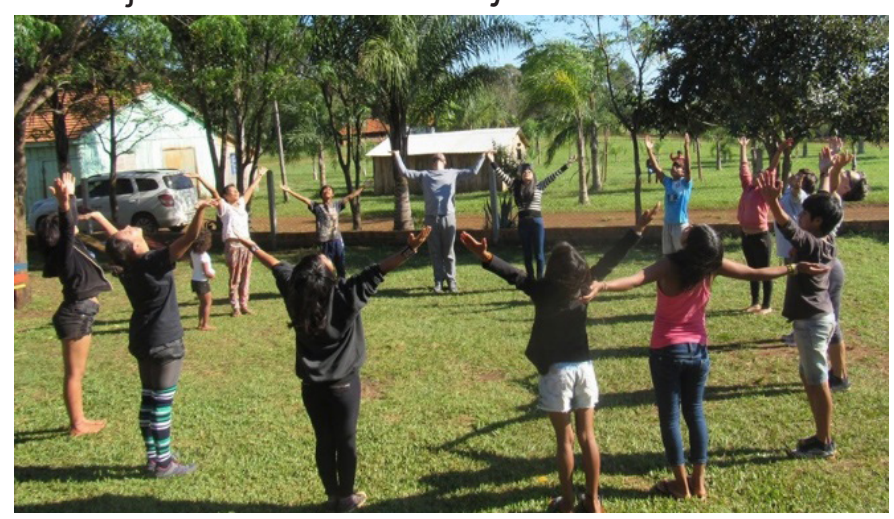

Fonte: Foto do arquivo dos autores.

Durante o processo (Fig. 2), fomos compartiIhando com as(os) Mbya-Guarani elementos de dança contemporânea (percepção/consciência corporal, contato improvisação, criações conjuntas), ao passo que elas(es) também compartilhavam conosco diferentes elementos de danças populares, festivas e autóctones que cultivavam. Na figura 2 estamos fazendo uma dança em forma de roda criada através da colagem dos movimentos que cada participante havia criado a partir da observação de formas existentes ao nosso redor (árvores, construções, animais, objetos etc.), exercício criativo ao qual aderiram com curiosidade explorativa e espontaneidade em relacionar-se com as formas observadas na aldeia e recriá-las no/com o corpo. Entre essas ricas partilhas de nossas danças, rodas de conversa e (con)vivências criativas, convidamos o grupo Mbya-Guarani para integrar conosco e o grupo de estudantes cidade de São Miguel o elenco do espetáculo Som e Luz em Corpos, convite que aceitaram com entusiasmo.

Já no início do processo criativo em vista da apresentação, as(os) professores(as) Mbya-Guarani que trabalharam conosco na oficina traduziram o texto do espetáculo Som e Luz para as(os) estudantes de modo que, pela primeira vez, puderam ouvir este na sua língua materna. No exercício de compreender e internalizar as imagens suscitadas pelo texto, as(os) estudantes Mbya-Guarani criaram seus movimentos, cenas e gestos para essas palavras-imagens, explorando suas habilidades de movimento e ampliando suas capacidades criadoras. Compreender o texto em sua língua também gerou estranhamentos e questionamentos sobre o fato de este ser a visão de um homem branco sobre a história de seus antepassados e, principalmente, sobre a narrativa docilizada e condescendente da atuação dos padres jesuítas ser muito diferente do que os pajés haviam contado a elas(es).

Sem poder modificar o roteiro gravado do espetáculo, pensamos em estratégias para não fazer da dança uma mera ilustração do texto, mas uma forma de fricção, como por exemplo, uma cena em que o padre jesuíta Antônio Sepp está descrevendo o cotidiano da redução e, ao passar pelos Guarani que estão dançando, dá pouca ou quase nenhuma atenção à sua dança. Nossa estratégia foi estender a coreografia para além da narrativa, seguir dançando insistentemente à revelia da indiferença do padre, fazendo da dança guarani por ele ignorada e da dança que hoje criamos com elas(es) uma forma de resistência e visibilidade.

[...] desde o primeiro trabalho dessa nossa arte, eu fiquei pensando um pouco mais sobre a intervenção nas Ruínas. [...] eu ia lá porque a minha mãe vendia artesanato, praticamente por isso. Eu vou porque eu tenho direito. Mas depois do nosso trabaIho eu acho que fiquei refletindo um pouco mais, quais intervenções se pode fazer mais, além dessas danças, porque foi uma grande intervenção que fizemos com as crianças. Foi pouco, na verdade deveria ter acontecido mais. As crianças também estão gostando. [...] Desde o nosso trabalho, desde que começamos esse trabalho, realmente fiquei refletindo mais. Também sobre as falas do Som e Luz. (informação verbal) ${ }^{5}$.

5 Entrevista com Patricia Ferreira, professora Mbya-Guarani da Escola Estadual Indígena de Ensino Fundamental Igineo Romeu Koenjú, da Aldeia Tekoá Koenjú, de São Miguel das Missões, realizada em 02 de setembro de 2020. Arquivo dos autores. 
No relato da professora Mbya-Guarani que atuou conosco nas oficinas, percebemos elementos do que significou esse trabalho artístico para ela e para as(os) estudantes, seu olhar e seus questionamentos sobre o patrimônio histórico - Ruínas de São Miguel e sua presença nesse espaço, e também a satisfação das crianças (estudantes) em protagonizar uma apresentação artística neste lugar. Esse processo artístico-pedagógico também plantou uma semente de questionamento acerca do texto do espetáculo de Som e Luz e do que ele fala sobre as e os Guarani, e como, ao entender essa narrativa na sua língua, elas(es) podem construir questões, críticas e posicionamentos performativos, abrindo caminhos e o desejo de criar outras formas de intervenção nesse espaço.

Durante os meses de outubro a dezembro de 2019, ver as(os) Mbya-Guarani ensaiando e apresentando-se no Sítio Histórico de São Miguel Arcanjo (Fig. $3)$, lugar onde seus antepassados viveram, foi impactante para todas(os) nós. Em sua motivação, atenção e dedicação, percebemos como esta experiência artístico-pedagógica afetava suas ações cotidianas. O mo(vi)mento de estarem em cena, de protagonizarem essa versão da história de seus antepassados, contribuiu para ressignificarem seus sentimentos de pertença àquele espaço - que por direito era e é deles! -, através da dança criada de modo coletivo, em atenção a um pedido delas(es) próprias(os). A motivação para as apresentações era tanto das(os) jovens estudantes como seus pais e mães Mbya-Guarani que com esmero providenciavam e organizavam os arcos, flechas, cestos e colares para compor os objetos cênicos e os figurinos das(os) filhas(os) e demais artistas para aprimorar a apresentação (Fig. 3).
Figura 3 - Estudantes indígenas e não indígenas no espetáculo Som e Luz em Corpos. Sítio Histórico de São Miguel Arcanjo. Dezembro/2019.

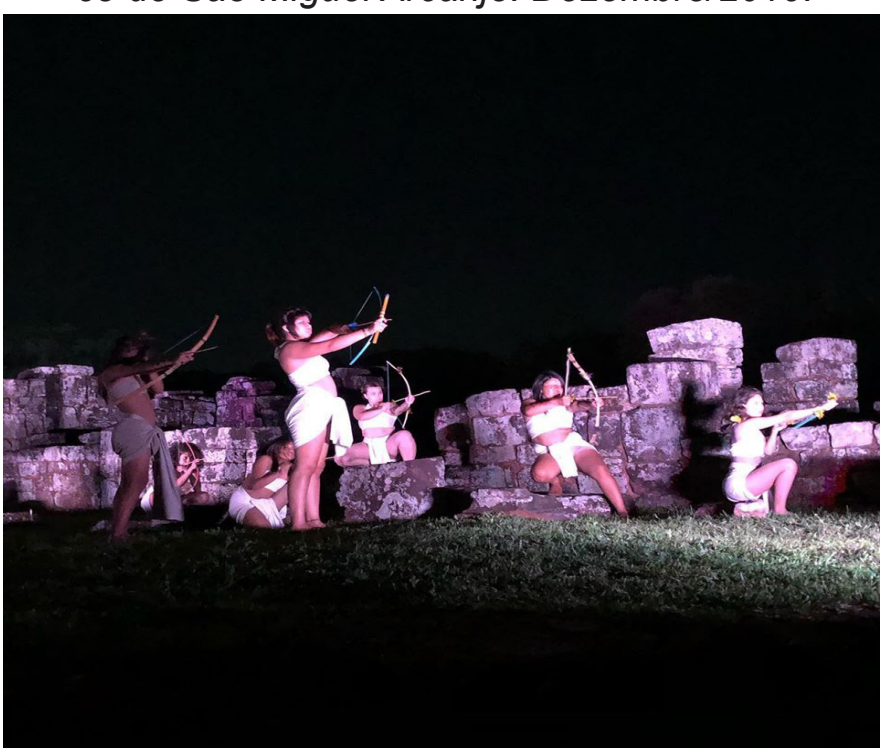

Fonte: Foto do arquivo dos autores.

Conforme destaca Berté, consideramos esta "uma dança que primeiramente descolonializa a nós próprios", como indivíduos não indígenas, formadores, professores, artistas, e também tem sido um modo "dos/as Guarani habitarem o patrimônio, [...] interpelando os olhares turísticos e a estetização do patrimônio com sua presença corporal, viva e atuante nesse espaço" (BERTÉ, 2020, p. 114-115). Com sua persistência, singeleza e potencial criativo, elas(es) têm nos ensinado um modo concreto de Ecologia dos Saberes em dança na qual estar com o diferente, sentir/ver como ele se move, pisa, olha e sorri, é um dançar junto que prepara, motiva e interpela a dança que vem depois e será compartilhada com o público. Desde esse sonhado "Sul" de nossas abordagens epistemológicas temos buscado caminhos de resistência e descolonização no nosso fazer em dança. Junto às(aos) Mbya-Guarani temos nos (trans)formado enquanto formamos futuras(os) licenciadas(os) em dança, alargando as maneiras de pensar-fazer arte e o que, com ela, podemos "revolusonhar". 
"De água seus sonhos":

é possível "revolusonhar"?!

O filósofo indígena brasileiro Ailton Krenak nos lembra que "a Ecologia dos Saberes deveria integrar nossa experiência cotidiana, inspirar nossas escolhas sobre o lugar em que queremos viver, nossa experiência como comunidade" (2019, p. 24). Mais que um baú de princípios éticos ao qual recorremos quando algo não vai bem, a Ecologia dos Saberes é para ser e estar tramada ao nosso (con)viver, fazer, sonhar. Ao refletir sobre como nosso tempo é especialista em criar ausências do sentido da própria experiência de vida e do convívio social, Krenak reflete sobre a intolerância

[...] com relação a quem ainda é capaz de experimentar o prazer de estar vivo, de dançar, de cantar. [...] Então pregam o fim do mundo como uma possibilidade de fazer a gente desistir dos nossos sonhos. [...] Cantar, dançar e viver a experiência mágica de suspender o céu é comum em muitas tradições. Suspender o céu é ampliar o nosso horizonte [...]. É enriquecer as nossas subjetividades, que é a matéria que esse tempo que nós vivemos quer consumir. (KRENAK, 2019, p. 26-32).

A dança contemporânea não se equivale às danças autóctones das(os) Mbya-Guarani, no entanto, no hall de possibilidades e estilos das danças cênicas, esta é a forma de pensar-fazer dança que mais tem nos permitido considerar o sujeito que dança e suas experiências, valorizar as possibilidades do corpo, a experimentação e as diferenças, viabilizando caminhos para uma potente relação com os pressupostos da Ecologia dos Saberes, das Epistemologias do Sul e da Pedagogia da Autonomia. Nos modos como realizamos o trabalho artístico-pedagógico com as(os) Mbya-Guarani, buscamos articular o que chamamos de "metodologias do Sul" para fazer-pensar dança com o outro, e não para/sobre o outro.

Motivadas(os) por esta potente vivência com as(os) Mbya-Guarani e entendendo o quanto ela contribuiu para a formação das(os) licenciandas(os) em dança, alcançamos incluir no novo Projeto Pedagógico do curso de Dança - Licenciatura da UFSM, em
2019, a disciplina específica de Estudos das Danças de Matrizes Indígenas Brasileiras. Ao incluir conteúdos históricos relativos a essas danças que precederam a chegada das danças europeias no Brasil, conteúdos pedagógicos acerca de como abordá-las no ensino, e experimentações de criação a partir de algumas dessas matrizes, a referida disciplina não objetiva um resgate nostálgico e repetições estereotipadas, mas um estudo acerca da arte indígena que dialoga com as tradições e se expressa em diferentes fazeres artísticos no mundo contemporâneo. Almejamos que um(a) docente indígena possa ministrá-la, e enquanto não for um deles a ocupar esse espaço, temos buscado manter o diálogo com colaboradores indígenas que nos auxiliam partilhando seus saberes.

"Eram de terra seus corpos, sem desejarem diferentes, de água seus sonhos cantando líquidas elegias, de ar a formosura de suas vestes do dia a dia, e a vontade de viver e seus amores, como fogo eram ardentes." (GAZZANA, 1978, p. 13). Inspiradas(os) pela poesia do texto do Som e Luz e do pensamento de Krenak, vemos na dança uma maneira de entretecer a Ecologia dos Saberes e a vida, uma possibilidade de suspender o céu - ampliar nossos horizontes - enriquecer nossas subjetividades, não desistir dos nossos sonhos, e "revolusonhar" em meio aos tempos sombrios que temos vivido. Na perspectiva de descolonização dos corpos, percebemos que essa experiência foi importante na formação das(os) licenciandas(os) em dança, pois as(os) colocou em contato direto com o diferente na cultura, na língua, na identidade, nos modos de se mover e entender o que é a dança, e, de modo dialógico, possibilitou criarem dança juntas(os).

\section{Referências}

BARBOZA, Mônica Corrêa de Borba. A formação nas licenciaturas em Dança das universidades públicas federais gaúchas pela voz das(os) docentes formadoras(as): o que é que essas(es) "profes" têm?, 239f. (Tese de Doutorado). Programa de Pós-Graduação em Educação. Universidade Federal de Pelotas - UFPel. 2019. 
BERTÉ, Odailso. "Olhem só, eles agora estão dançando": habitar o patrimônio cultural com os/as Mbyá-Guarani. In.: VIEIRA, Marcilio de Souza. (Org.). Escritos sobre dança. Natal: ANDA, 2020.

BERTÉ, Odailso; BORBA, Mônica; CASTRO, Crystian. O processo criativo do Som e Luz em Corpos. In.: CASTRO, C.; BORBA, M.; BERTÉ, O. (Orgs). "Quem vem lá?": (mo)vendo com o Som e Luz em Corpos. Santa Maria/RS, UFSM, PRÉ, 2019.

BERTÉ, Odailso. Dança contem(pop): corpos, afetos e imagens (mo)vendo-se. Santa Maria: Ed. UFSM, 2015.

CASTRO, Crystian; BERTÉ, Odailso. Autonomia dos corpos em tempos de repressão: para pensar processos criativos e formativos em dança. In.: SENNA, Nádia da Cruz; SILVA, Úrsula da Silva (Orgs.). Anais do III Seminário Internacional Ensino da Arte: o avesso das práticas. Pelotas: Ed. da UFPel, 2017.

FREIRE, Paulo. Pedagogia da autonomia: saberes necessários à prática educativa. $51^{\mathrm{a}} \mathrm{Ed}-\mathrm{Rio}$ de Janeiro: Paz e Terra, 2015.

GAZZANA, Henrique Grazziotim. Som e Luz. Governo do Estado do Rio Grande do Sul. Secretaria da Cultura e Turismo. Porto Alegre: Grafosul, 1978.

ICLE, Gilberto. O que é Pedagogia da Arte? In.: ICLE, Gilberto (Org.). Pedagogia da Arte: entre-lugares da escola. Porto Alegre: Editora UFRGS, 2012.

KRENAK, Ailton. Ideias para adiar o fim do mundo. São Paulo: Companhia das Letras, 2019.

MARQUES, Isabel. Ensino de Dança hoje: textos e contextos. São Paulo: Cortez, 2008.
RESCHKE, Maria Janine Dalpaiz. Coerência e contradição: o conteúdo e a forma no exercício da docência em didática nos cursos de licenciatura. 2014. 125f. (Tese de Doutorado). Programa de Pós-Graduação em Educação, Universidade do Vale dos Sinos - UNISINOS, 2014.

SANTOS, Boaventura de Sousa. A gramática do tempo: para uma nova cultura política. $3^{a}$ ed. São Paulo: Cortez, 2010.

. O fim do império cognitivo: a afirmação das epistemologias do Sul. Belo Horizonte: Autêntica, 2019.

UFSM, Universidade Federal de Santa Maria. Projeto de Extensão De Terra Seus Corpos. 2018.

Recebido: 08/01/2021

Aceito: 05/05/2021

Aprovado para publicação: 28/05/2021

Este é um artigo de acesso aberto distribuído sob os termos de uma Licença Creative Commons Atribuição 4.0 Internacional. Disponível em: http://creativecommons.org/licenses/by/4.0.

This is an open-access article distributed under the terms of the Creative Commons Attribution License 4.0 International. Available at: http://creativecommons.org/licenses/by/4.0.

Ce texte en libre accès est placé sous licence Creative Commons Attribution 4.0 International. Disponible sur: http://creativecommons.org/licenses/by/4.0. 